\title{
LIST OF SUPPORTING FIGURES
}

Figure S1. X-ray diffraction patterns for reference compounds used in the XPS analysis, including $\mathrm{Li}_{3} \mathrm{PO}_{4}$ (Alfa Aesar, Puratronic, 99.99\%), $\mathrm{AlPO}_{4}$ (Alfa Aesar, Puratronic, 99.99\%), $\mathrm{LiAlO}_{2}$ (Alfa Aesar), $\mathrm{Li}_{2} \mathrm{CO}_{3}$ (Alfa Aesar, Puratronic, 99.999\%), and $\mathrm{LiAl}_{0.1} \mathrm{Co}_{0.9} \mathrm{O}_{2}$, which was prepared by the solid-state method from $\mathrm{CoCO}_{3}, \mathrm{Li}_{2} \mathrm{CO}_{3}$, and $\mathrm{Al}\left(\mathrm{NO}_{3}\right)_{3}$, heated at $500{ }^{\circ} \mathrm{C}$ for 1 hour and annealed at $900{ }^{\circ} \mathrm{C}$ for 12 hours. XRD measurements were performed on a Rigaku RU300 diffractometer with $\mathrm{Cu} \mathrm{K}_{\alpha}$ radiation at room temperature. Patterns were measured between $10-140^{\circ}$ of $2 \theta$, at a scan rate of 2.0 degrees/min. Symbol $\left(^{*}\right)$ indicates peak of a minor impurity phase.

Figure S2. Voltage profiles of (a) bare " $\mathrm{LiCoO}_{2}$ ” and (b) “AlPO"-coated $\mathrm{LiCoO}_{2}$ during cycling at a $\mathrm{C} / 10$ rate for the $1^{\text {st }}$ cycle and $\mathrm{C} / 5$ rate for subsequent cycles, between voltage limits of $3.0 \mathrm{~V}$ and $4.7 \mathrm{~V}$. 


\section{SUPPORTING FIGURES}

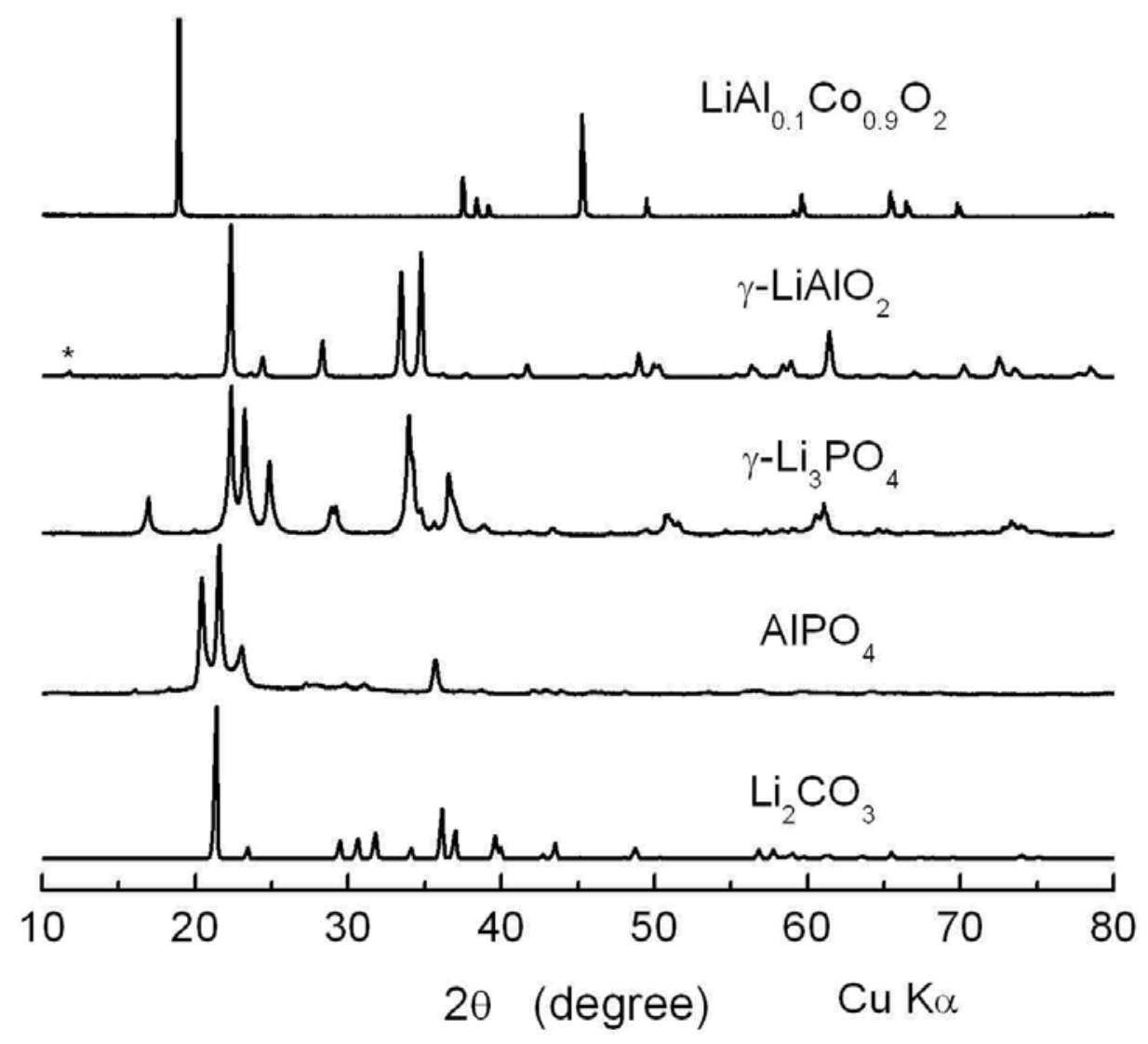

Figure S1. 
(a)

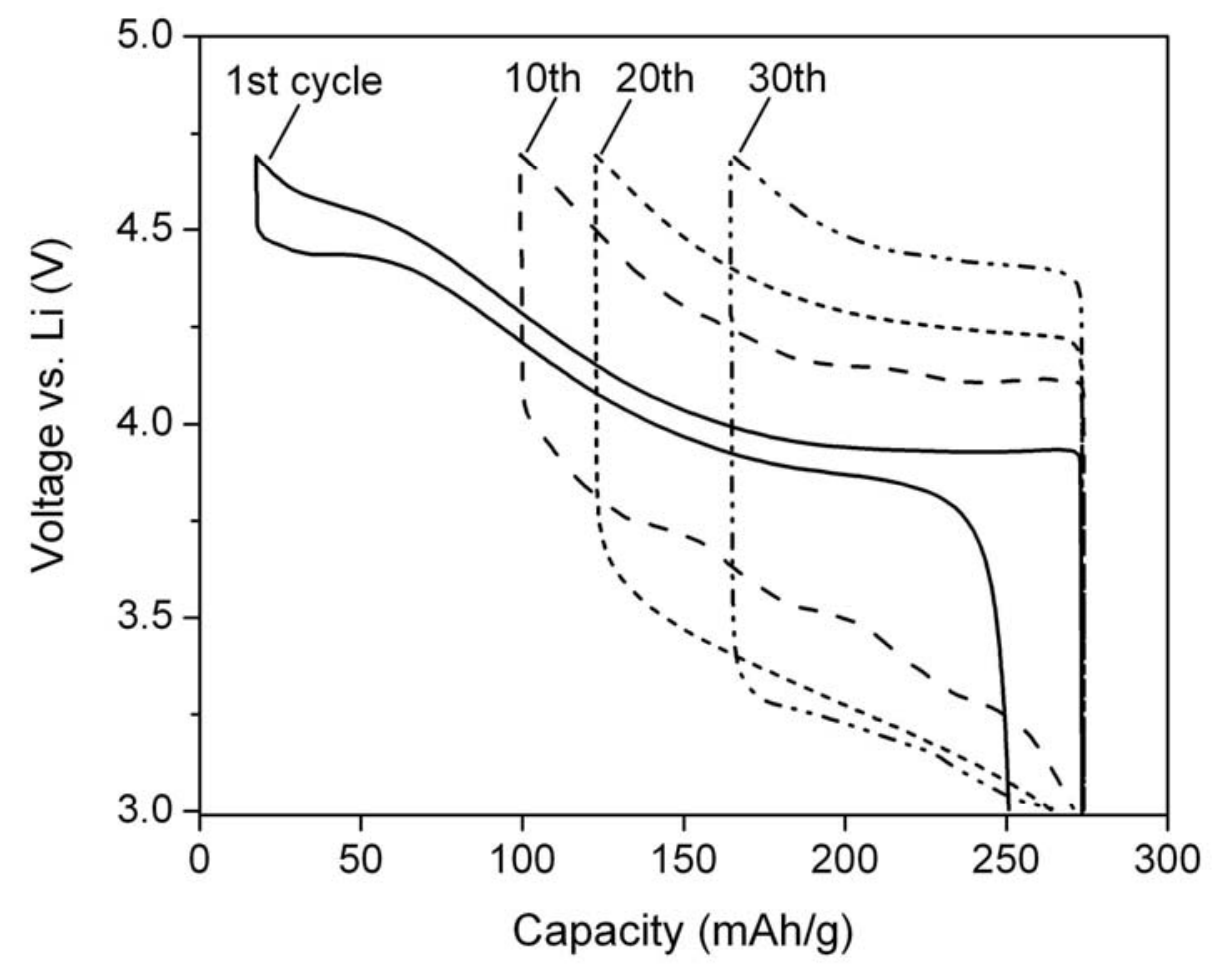

(b)

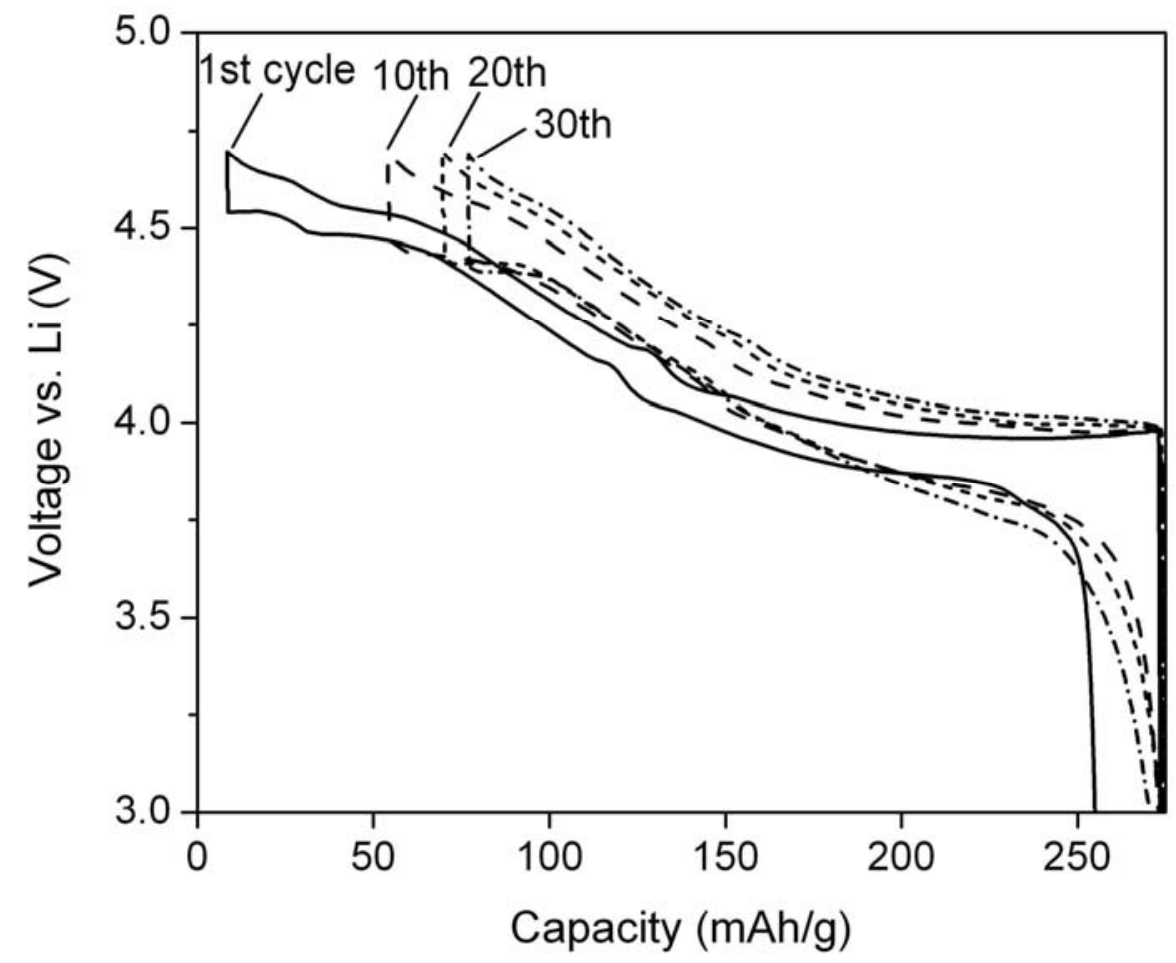

Figure S2. 